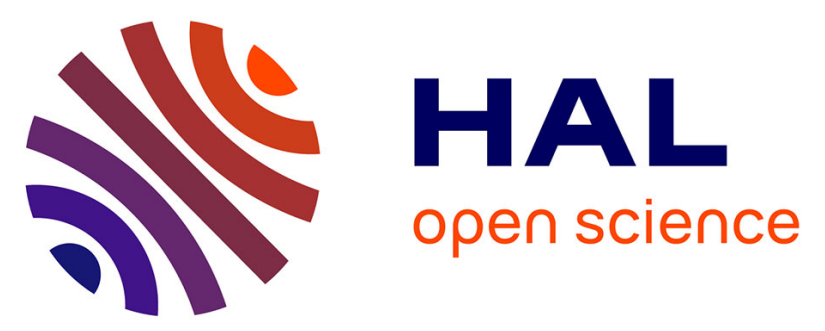

\title{
Continuous Symmetry Breaking Induced by Ion Pairing Effect in Heptamethine Cyanine Dyes: Beyond the Cyanine Limit
}

Pierre-Antoine Bouit, Christophe Aronica, Loic Toupet, Boris Le Guennic, Chantal Andraud, Olivier Maury

\section{To cite this version:}

Pierre-Antoine Bouit, Christophe Aronica, Loic Toupet, Boris Le Guennic, Chantal Andraud, et al.. Continuous Symmetry Breaking Induced by Ion Pairing Effect in Heptamethine Cyanine Dyes: Beyond the Cyanine Limit. Journal of the American Chemical Society, 2010, 132 (12), pp.4328-4335. 10.1021/ja9100886 . hal-01073293

\section{HAL Id: hal-01073293 https://hal.science/hal-01073293}

Submitted on 26 Nov 2019

HAL is a multi-disciplinary open access archive for the deposit and dissemination of scientific research documents, whether they are published or not. The documents may come from teaching and research institutions in France or abroad, or from public or private research centers.
L'archive ouverte pluridisciplinaire HAL, est destinée au dépôt et à la diffusion de documents scientifiques de niveau recherche, publiés ou non, émanant des établissements d'enseignement et de recherche français ou étrangers, des laboratoires publics ou privés. 


\section{Continuous Symmetry Breaking Induced by Ion Pairing Effect in}

\section{Heptamethine Cyanine Dyes: Beyond the Cyanine Limit. ${ }^{1}$}

Pierre-Antoine Bouit,$^{\dagger}$ Christophe Aronica, ${ }^{\dagger}$ Loïc Toupet, ${ }^{\dagger}$ Boris Le Guennic, ${ }^{\dagger}$ Chantal Andraud $^{\dagger}$ and Olivier Maury ${ }^{\dagger *}$.

University of Lyon, Laboratoire de Chimie, UMR 5182 CNRS - Ecole Normale Supérieure de Lyon, 46 allée d'Italie,69007Lyon,France.E-mail : olivier.maury@ens-lyon.fr

UMR 6226 CNRS-University of Rennes 1, Campus de Beaulieu, 35042 Rennes, France 


\section{Introduction.}

Since their initial use as sensitizer for silver halide emulsion photography, streptopolymethine dyes (or polymethine dyes) ${ }^{2}$ have been continuously studies in material science for numerous applications in optoelectronic, nonlinear optics, optical data storage, photovoltaism, electroluminescence... ${ }^{3}$ More recently, they found promising potentialities in biology as photodynamic therapy agents or bio-probes for near infra-red imaging (NIR). ${ }^{4}$ The main peculiarity of polymethine dyes consists in the odd number of $s p^{2}$ carbon atoms chain forming the $\pi$-conjugated bridge between electron donating and/or accepting groups, controlling the photophysical and structural properties of the dye. This family can be divided in two sub-classes featuring very different structural, electronical and optical properties, depending on the charge of the dye, the neutral (even zwitterionic) merocyanine and charged (cationic or anionic) cyanine. The merocyanine sub-class can be represented using three different resonance limit structures $\left(\boldsymbol{M}^{1-3}\right)$ formalized by Dähne in the early 1970's (Figure $1):^{5}$

(i) The neutral ground state $\left(\boldsymbol{M}^{\boldsymbol{I}}\right)$ for weak to moderate electron donating and withdrawing groups. This polyene-like form is characterised structurally by a maximal bond length alternation (BLA) between single and double bond ${ }^{6}$ and optically by a broad intense charge transfer transition (CT) featuring positive solvatochromism.

(ii) The opposite zwitterionic case $\left(\boldsymbol{M}^{3}\right)$ where a complete charge separation occurs under the effect of very strong donor and acceptor fragments. This bipolar polyene structure also called betaine, presents opposite also maximal BLA and a broad CT transition but with a negative solvatochromism. 
(iii) Between these two limit structures, for a certain ratio between electron donating and accepting character, the charge of the end-groups equalized and the BLA vanished. This very particular structure $\left(\boldsymbol{M}^{3}\right)$ is called "cyanine limit".

In this merocyanine sub-class, it is possible to control the neutral or zwitterionic character of the ground state by fine tuning the strength of the electron donating or accepting end-groups or thanks to the solvent polarity effects (solvatochromism). It is therefore possible to cross this virtual cyanine limit ${ }^{7}$ and in some rare cases to stabilize a merocyanine dye close to this ideal cyanine structure. ${ }^{8}$

This cyanine structure, very difficult to obtained from dissymmetric merocyanine dye, can be directly prepared by the association of two identical donor or more scarcely acceptor end-groups via a polymethine chain featuring an odd number of $s p^{2}$ carbons atoms. ${ }^{9}$ These molecules spontaneously reach the ideal polymethine state (IPS) presenting unique structural and spectral characteristic (Figure $1, \boldsymbol{M}^{2}$ ): as a results of the two degenerated dominant resonant forms with the charge localised at one or the other end-group $\left(\boldsymbol{M}^{\boldsymbol{1}}=\boldsymbol{M}^{\boldsymbol{3}}\right)$, the polymethine chain is a non alternating structure with an average "one and half" bond length $(\mathrm{BLA}=0)$. This lack of bond alternation is experimentally confirmed by most of the crystal structures reported in the literature. ${ }^{9 \mathrm{~A}, 10}$ From a spectroscopic point of view, cyanine in their IPS are characterized by a sharp, extremely intense absorption band (Figure 1) resulting from the reduced vibronic contribution in these non alternating structure. This very particular transition called solitonic by analogy with doped polyacetylene, is shifted in the NIR spectral range. The complete rationalisation of this transition using theoretical model remains a matter of debate; in particular the clear assignment of the high energy shoulder remains problematic. ${ }^{11}$ This ideal polymethine state is conserved in the case of relatively short $\pi$ conjugated chain (up to 9-13 carbon atoms depending on the structure) but is progressively lost for longer chain. As a consequence, upon increasing the chain length, the sharp transition 
characteristic for the IPS state undergoes a bathochromic shift (c.a. $100 \mathrm{~nm}$ per additional vinylic unit, Figure 2, curve a) followed by a profound modification of the spectrum with a large broadening of the band and a decrease of its intensity (Figure 2, curve b). ${ }^{1,12}$ This chainlength dependence of the spectroscopic properties, generally referred as Brooker experiment, ${ }^{13}$ was rationalised first by Tolbert and co-workers ${ }^{1}$ invoking a "symmetry collapse" for long chain cyanine electronic structure due to Peierl-type distortions. In this later case, the cyanine initially in its symmetric IPS form can be better described by a dipolar asymmetric form (Figure 2) resulting in the apparition of a broad Charge-Transfer type transition. This symmetry-lowering distortion was recently confirmed by theoretical calculations. ${ }^{12,14}$ In addition, Lepkowicz, Hagan and co-workers reported that for a given cyanine, featuring a 11 carbon conjugated chain, it is possible to cross the "cyanine limit" by increasing the solvent polarity. ${ }^{15}$ The observed polar solvatochromism, characteristic of pushpull dyes featuring a large ground state dipole moment allows the authors to conclude that "polymethine chain may exist in the ground state in two charged forms with symmetrical and asymmetrical distribution of charge density" (Figure 2). The existence of the asymmetric form was further evidenced by X-ray crystallography only in the case of a particular trimethynecyanine $\left[\mathrm{Mc}\left(\mathrm{CH}_{2}\right)_{3} \mathrm{Mc}\right]^{+}$featuring ruthenocenyl donor $(\mathrm{Mc})$ end group. ${ }^{16}$ This result is quite surprising because the cyanine is very short, which generally favors symmetrical form, and because the ferrocenyl analogous remains symmetrical. The authors explain these distortions by electronic effects rather than by solid-state crystal packing effects. In summary, it has been demonstrated to date that the cyanine limit can be crossed by modification of the donor end-group, by lengthening the conjugated skeleton or of for a given cyanine by increasing the solvent polarity. It is worth noting that the influence of the counteranion on the cationic cyanine properties was completely neglected amount the large literature devoted to this class of chromophores. One can mention the woks of Schuster and co-workers 
in the 1990's that reported the induction of circular dichroism by interaction between cyanine salts and chiral borate anion. ${ }^{17}$ In this context, we recently described the diastereoselective supramolecular interaction between TRISPHAT anion and heptamethine cyanine $\mathbf{1}^{+}$(Figure 3). ${ }^{18}$ In this article, we presented a combined crystallographic-spectroscopic study of the influence of the counter-anion $\mathrm{A}\left(\mathrm{A}=\mathrm{Br}^{-}, \mathrm{I}^{-}, \mathrm{PF}_{6}^{-}, \mathrm{SbF}_{6}^{-}, \mathrm{B}\left(\mathrm{C}_{6} \mathrm{~F}_{5}\right)_{4}{ }^{-}\right.$, TRISPHAT $)$on the solution and solid state properties of the 1.[A] cyanine salt (Figure 3). Whereas ideal polymethine state is conserved in the case of large counter-anion, the formation of ion-pair with small counter-ion will favour the unsymmetrical form.

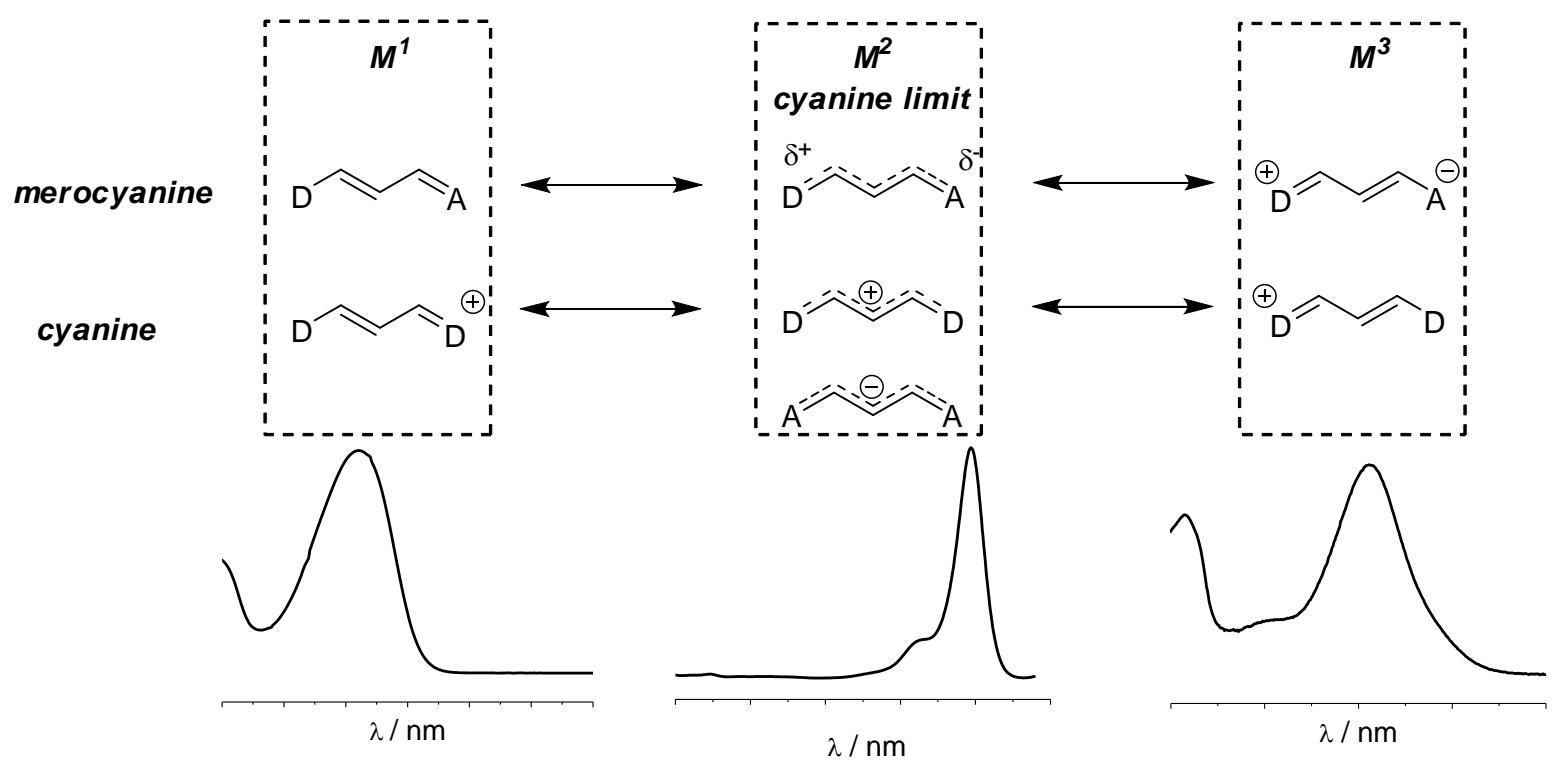

Figure 1. Different resonance forms envisaged for push-pull chromophores and related shape of the absorption spectra (bottom).

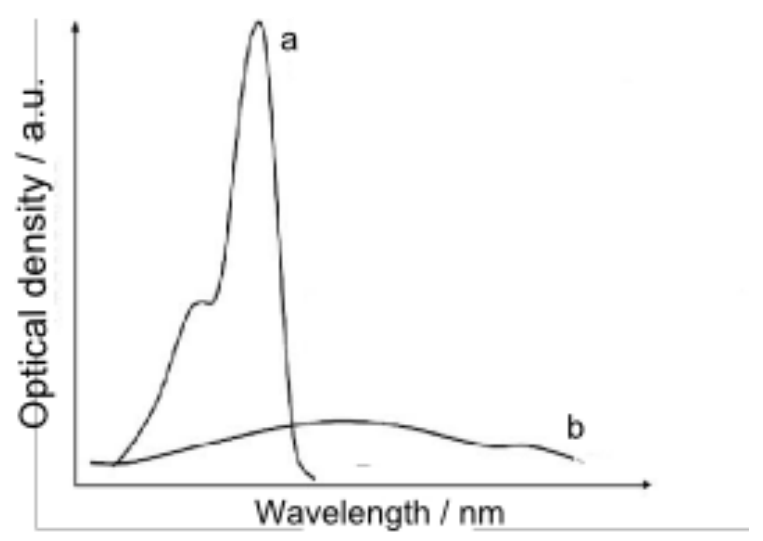

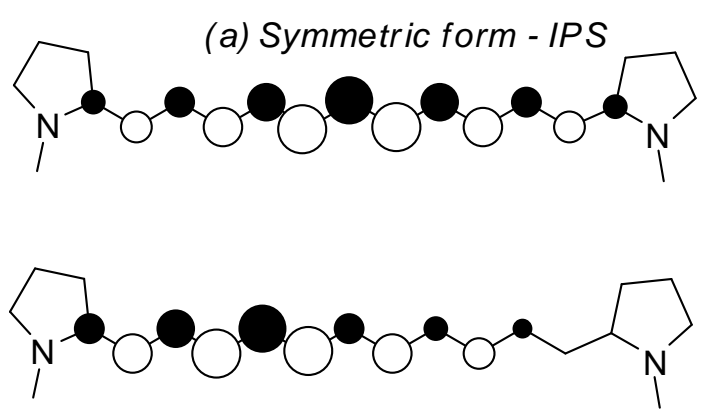

(b) Asymmetric form - dipolar state 
Figure 2. Spectral and electronic modifications by crossing the cyanine limit.

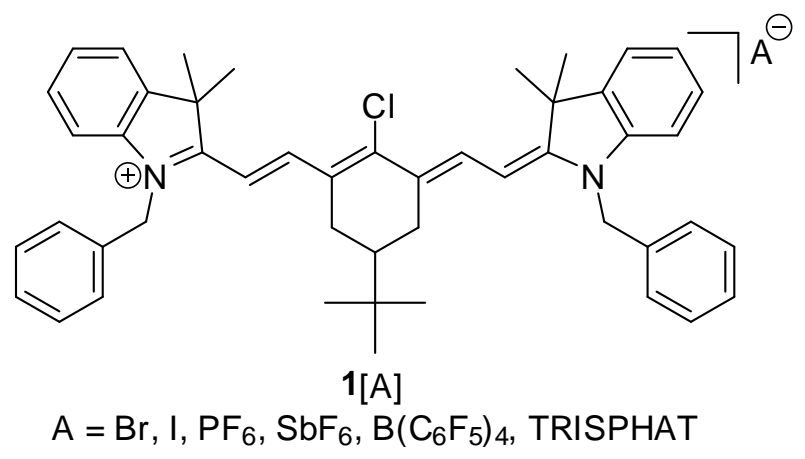

Figure 3. Molecular structure of cyanine cation and associated anions.

Synthesis. The synthesis of $\mathbf{1}[\mathrm{Br}]$ was achieved using classical procedures and was used as starting material for all anion exchange reactions. The displacement of the bromide anion required an excess of $\mathrm{NaI}, \mathrm{NaPF}_{6}, \mathrm{NaSbF}_{6}$ but only one equivalent of the more lipophilic $\left[\mathrm{HNBu}_{3}\right]\left[\right.$ TRISPHAT] or $[\mathrm{Li}]\left[\mathrm{B}\left(\mathrm{C}_{6} \mathrm{~F}_{5}\right)_{4}\right] . \mathrm{Et}_{2} \mathrm{O}$ salts. All the products 1.[Br], 1.[I], 1. $\left[\mathrm{PF}_{6}\right], 1 .\left[\mathrm{SbF}_{6}\right], 1 .[T R I S P H A T], 1 .\left[\mathrm{B}\left(\mathrm{C}_{6} \mathrm{~F}_{5}\right)_{4}\right]$ were purified by extraction, filtration on a silica plug and crystallisation from toluene-chloroform (or methanol) mixtures (see experimental section). The resulting single crystals featuring all a metallic shine were further used for crystallography or spectroscopy experiments.

\section{Structural inspection.}

II.1 Gaz phase structure. The gaz phase structure of the cation 1'+ lacking in counter-anion featuring $\mathrm{N}-\mathrm{Me}$ instead of $\mathrm{N}$-Ben moieties was obtained using density functional theory calculations (See experimental section for computational details). The optimized structure of the syn conformation with both $\mathrm{NMe}$ groups opposite to $\mathrm{Cl}$ is calculated $3.3 \mathrm{kcal}^{\mathrm{mol}}{ }^{-1}$ more stable than the structure with both NMe on the same side than $\mathrm{Cl}$ in agreement with the structure obtained by X-ray crystallography (vide infra). The structure is perfectly planar without any twist of the carbon skeleton. The C-C bond lengths of 
the polymethyne backbone are very similar about $140.2 \pm 1 \mathrm{pm}$ (Table 1) comprised between single and double bonds. This perfectly non alternating structure is characteristic of an ideal polymethine state.

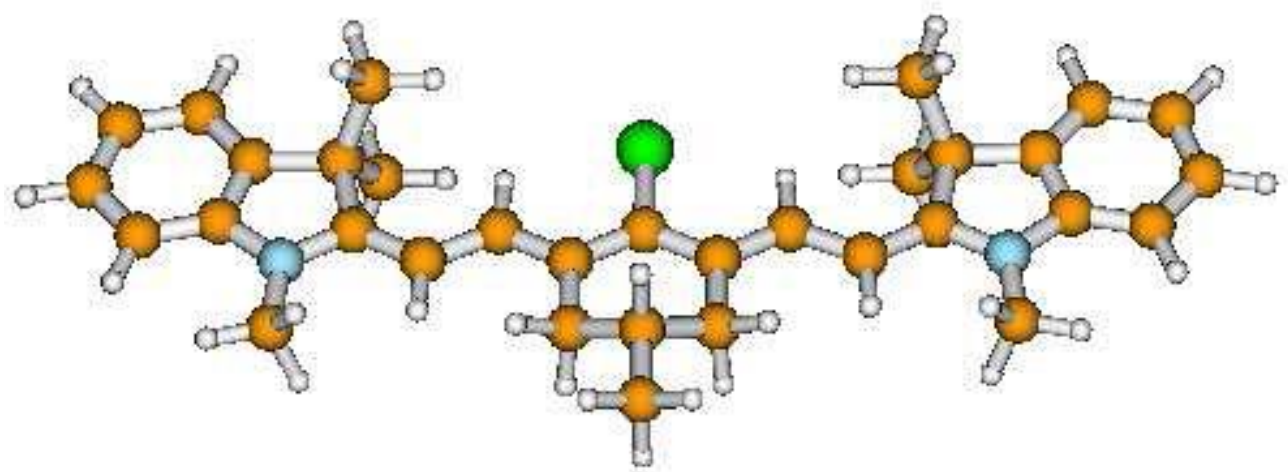

Figure 4. DFT optimized structure of $\mathbf{1}^{\text {’+}}$.

Table 1. C-C bond lengths determined by theoretical calculation or by crystallography.

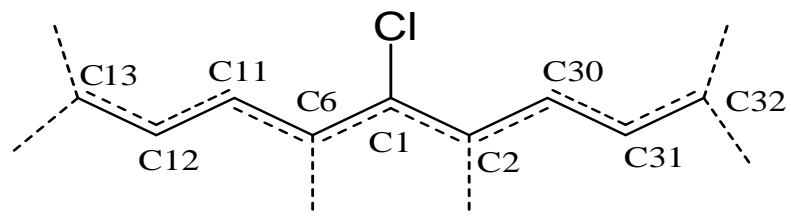

\begin{tabular}{|c|c|c|c|c|c|c|c|}
\hline $\begin{array}{l}\text { Liaison / } \\
\mathbf{1}[\mathrm{X}]\end{array}$ & $1^{\prime+d}$ & $\mathbf{1}[\mathrm{Br}]$ & $\mathbf{1}[\mathrm{I}]$ & $\mathbf{1}\left[\mathrm{PF}_{6}\right]$ & $\mathbf{1}\left[\mathrm{SbF}_{6}\right]$ & $\mathbf{1}\left[\mathrm{B}\left(\mathrm{C}_{6} \mathrm{~F}_{5}\right)_{4}\right]$ & $\mathbf{1}$ [TRISPHAT] \\
\hline C13-C12 & 139.6 & 141.2 & 139.4 & 138.1 & 140.9 & 139.3 & 139.1 \\
\hline C12-C11 & 140.0 & 136.0 & 139.4 & 137.5 & 137.0 & 136.4 & 139.1 \\
\hline C11-C6 & 140.1 & 140.5 & 140.0 & 139.5 & 140.6 & 140.3 & 139.0 \\
\hline C6-C1 & 141.2 & 137.1 & 139.5 & 138.0 & 138.4 & 139.5 & 140.2 \\
\hline $\mathrm{C} 1-\mathrm{C} 2$ & 141.2 & 142.3 & 143.8 & 141.0 & 142.3 & 139.9 & 140.7 \\
\hline C2-C30 & 140.1 & 135.9 & 137.2 & 138.7 & 139.5 & 139.2 & 138.6 \\
\hline C30-C31 & 140.0 & 142.4 & 140.8 & 139.7 & 139.6 & 138.7 & 139.8 \\
\hline C31-C32 & 139.6 & 134.8 & 136.7 & 136.8 & 138.5 & 138.3 & 137.5 \\
\hline
\end{tabular}




\begin{tabular}{llllllll}
\hline $\mathrm{l}_{1}{ }^{\mathrm{a}}$ & $\mathrm{Xxx}^{\mathrm{c}}$ & 141.6 & 141.0 & 139.6 & 140.8 & 139.5 & $\mathrm{xxx}^{\mathrm{c}}$ \\
$\mathrm{l}_{2}{ }^{\mathrm{b}}$ & $\mathrm{xxx}^{\mathrm{c}}$ & 135.9 & 138.2 & 137.8 & 138.3 & 138.3 & $\mathrm{xxx}^{\mathrm{c}}$ \\
$\mathrm{BLA}$ & $<0.1$ & 5.7 & 2.8 & 1.8 & 2.5 & 1.2 & $\mathrm{xxx}^{\mathrm{c}}$
\end{tabular}

${ }_{\mathrm{a}}$ Average short bond length ${ }^{\mathrm{b}}$ Average long bond length. ${ }^{\mathrm{c}}$ impossible to determine. ${ }^{\mathrm{d}}$ DFT optimized structure.

II.2 Solid state structures. X-rays diffraction analysis of the six cyanine salt crystals was performed (see experimental section for details), crystal data and refinement parameters were summarized in the Table 2. For clarity, the same atom numbering was used for the cyanine cation in each structure. At the molecular level the cyanine cation always presents the expected syn conformation with both $\mathrm{N}$-Ben moieties located at the opposite site to the chloride atom. The $\pi$-conjugated skeleton is planar with small overall tilt angle comprised between 8.6 and $30^{\circ}$. The planarity of the conjugated carbon chain is ensured by the fused central 6-members ring whose conformation is further constrained by the thermodynamically favored equatorial position of the tert-butyl fragment. The most striking difference observed between these six cyanine salts concerns the measure of the $\mathrm{C}-\mathrm{C}$ bond distances in the conjugated backbone and more precisely in the overall BLA defined here as the difference between the average of the short and the long C-C bond lengths (Table 1). The 1.[TRISPHAT] salt presents an almost perfectly non alternated structure, where it is not possible to discriminate between the short and long $\mathrm{C}-\mathrm{C}$ bond lengths. In this case, the BLA is almost zero as expected for cyanine in its IPS state. The structure of $\mathbf{1 . [ B r ] ~ s a l t ~ i s ~ i n ~ m a r k e d ~}$ contrast with the previous one since a clear alternation between short $(135.9 \mathrm{pm})$ and long (141.6 pm) C-C bond lengths is observed leading to a strong BLA value of $5.7 \mathrm{pm}$. This result indicates a significant breaking of the molecular symmetry further confirmed by the analysis of the terminal $\mathrm{C}-\mathrm{N}$ distances. The $\mathrm{N} 1-\mathrm{C} 13$ bond length is $133.6 \mathrm{pm}$ in the range of 
imine/iminium fragment whereas the N2-C32 bond measures $140.9 \mathrm{pm}$ closer to that of an amine moieties. In the 1.[Br] salt, the cyanine cation looses its IPS state, the molecule being polarized with one amino- and one iminium-like moieties at each extremity bridged by an alternating $\pi$-conjugated backbone. 1. $[\mathrm{Br}]$ presents very closed structural properties with the dipolar compound $\mathbf{2}$ in which a tricyanofurane accepting group is associated with an amino donor group via the same conjugated bridge and which exhibits a BLA value of $6.2 \mathrm{pm}$ (Figure 5). To the best of our knowledge, 1.[Br] is the only heptamethine structure featuring a so marked dipolar character. ${ }^{19}$ The structures of the four other salts are intermediate between these two limits, i.e. IPS and dipolar forms. The BLA is strongly dependant of the nature of

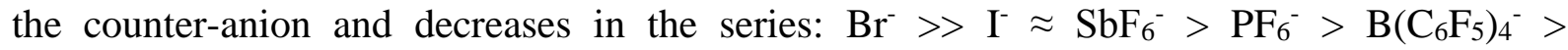
TRISPHAT (Table 1). To get deeper insight into these solid state effects, a careful examination of the crystal packing was undertaken.

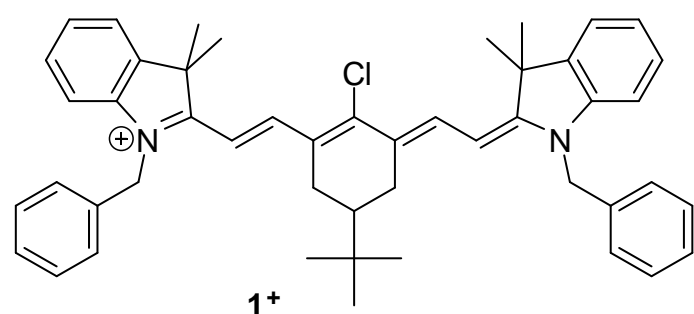

$\mathrm{BLA}=5.7 \mathrm{pm}$ assymetric form in the case of $\mathrm{Br}^{-}$counter anion<smiles>CC1(C)OC(=C(C#N)C#N)C(C#N)=C1C=CC1CC(C(C)(C)C)CC(C=C2N(Cc3ccccc3)c3ccccc3C2(C)C)=C1Cl</smiles>
Dipolar chromophore 2

\section{Cyanine limit}

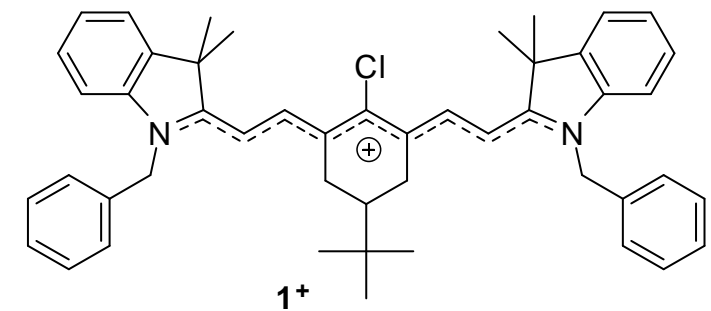

BLA $<1 \mathrm{pm}$ symetric form in the case of TRISPHAt or $B\left(\mathrm{C}_{6} \mathrm{~F}_{5}\right)_{4}$ counter anion

Figure 5. Different electronic structures observed for the cyanine cation $\mathbf{1}^{+}$. 
In spite of their large BLA difference, 1.[Br] and 1.[I] are isostructural and crystallized in the $\mathrm{P} 2{ }_{1} / c$ space group. The crystal lattice is made of zig-zag double layers of stacked cations separated by sheets of halogenide anions (Figure 6, up). Each cation is surrounded by seven nearest anions within a radius of $10 \AA$. Whereas N1 is closed to three halogenides $(\mathrm{d}(\mathrm{N} 1-\mathrm{Br})=4.74,4.86$ and $6.95 \AA ; \mathrm{d}(\mathrm{N} 1-\mathrm{I})=4.86,5.01$ and $6.88 \AA), \mathrm{N} 2$ presents four anionic neighbors $(\mathrm{d}(\mathrm{N} 2-\mathrm{Br})=6.91,7.04,8.18$ and $8.55 \AA$; $(\mathrm{N} 2-\mathrm{I})=6.91,7.02,8.10$ and $8.56 \AA)$ (Figure 6, bottom). Therefore, from a pure structural point of view, in the case of $1 .[\mathrm{Br}]$ and 1.[I], the anionic environment of the cyanine is clearly unsymmetrical and can be considered as responsible for the polarisation of the polymethine chain, the nitrogen atom featuring an iminium character being located in the shortest anionic neighborhood. But this crystallographic description is insufficient to explain alone the difference of BLA magnitude observed between the two compounds (Table 1). The nature of the anion has to be taken into account. Indeed, according to the HSAB theory (Pearson's hard and soft acid base theory) point of view, a stronger polarization is expected upon interaction with a hard counter-ion. In the present case, bromide featuring the same charge but a smaller ionic radius than iodide can be considered as a harder anion. In consequence, for a given interaction (same distance, same anionic surrounding) bromide polarize more strongly the polymethine chain than iodide. 


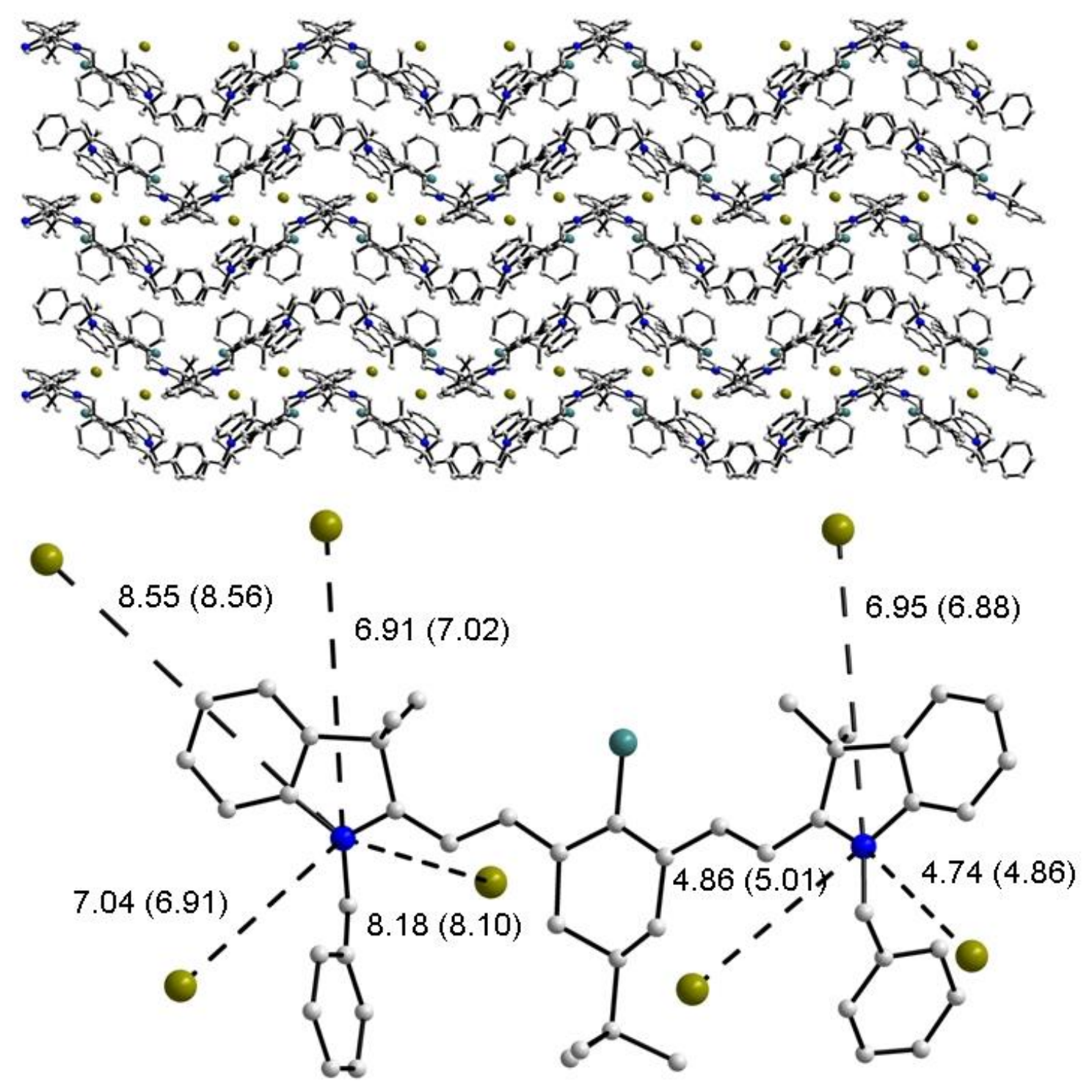

Figure 6. (up) View of the crystal packing of 1.[Br] according to the $c$ axis. (bottom) Nearest anionic environment of the cyanine cation in the cases of $1 .[\mathrm{Br}]$ and $1 .[\mathrm{I}]$ between parenthesis, respectively.

1. $\left[\mathrm{PF}_{6}\right]$ and 1. $\left[\mathrm{SbF}_{6}\right]$ form also a pair of isostructural compounds crystallizing in the centrosymmetric $P-1$ space group. The crystal lattice is constituted of parallel double-layers of cations separated by a single sheet of counter-anions (Figure 7, up). In these structures, the anionic surrounding is composed by six anions, among which one interacts with both sides of the cyanine. Two shorter anion-cation distances, responsible for the stronger electrostatic 
interaction are observed on both sides of the molecule $(\mathrm{d}(\mathrm{N} 1-\mathrm{P})=\mathrm{d}(\mathrm{N} 2-\mathrm{P})=4.81 \AA$ and $\mathrm{d}(\mathrm{N} 1-\mathrm{Sb})=5.02$ and $\mathrm{d}(\mathrm{N} 2-\mathrm{P})=4.84 \AA$ ) , the other anions being located far away, at a distance higher than $7 \AA$ (Figure 7 ). Consequently, the cation environment is much more symmetrical than in the previous 1.[Br] and 1.[I] compounds. This is also the case for the 1. $\left[\mathrm{B}\left(\mathrm{C}_{6} \mathrm{~F}_{5}\right)_{4}\right]$ crystal structure where the cation interacts symmetrically with six borate anions (Figure 8) located at a quite long distance due to the large steric hindrance induced by this bulky anion $(\mathrm{d}(\mathrm{N} 1-\mathrm{B})=6.99,7.81,9.41 \AA$ and $\mathrm{d}(\mathrm{N} 2-\mathrm{B})=6.96,8.61,8.10,9.67 \AA)$. In these three cases, the anionic surrounding of the cyanine cation is clearly much symmetrical. Whatever the nature of the anion, this symmetric environment results in a very small polarization of the polymethine chain compared to 1 .[Br]. Finally, in case of 1.[TRISPHAT], a diastereoselective supramolecular interaction occurs between the TRISPHAT anion and the pro-chiral cyanine anion. ${ }^{19}$ As a result, the cation presents a close interaction with one anion $(\mathrm{d}(\mathrm{N} 1-\mathrm{P})=5.22 \AA)$ and long distance ones with four other anions (Figure 9). In spite of this unsymmetrical environment, the polymethine chain remains absolutely not polarised $(B L A=0$, Table 1$)$. The TRISPHAT anion is bulky and the negative charge is delocalized on the three tetrachlorophenyl accepting moieties. It can therefore be considered as a soft anion, unable to induce any electronic polarization. 


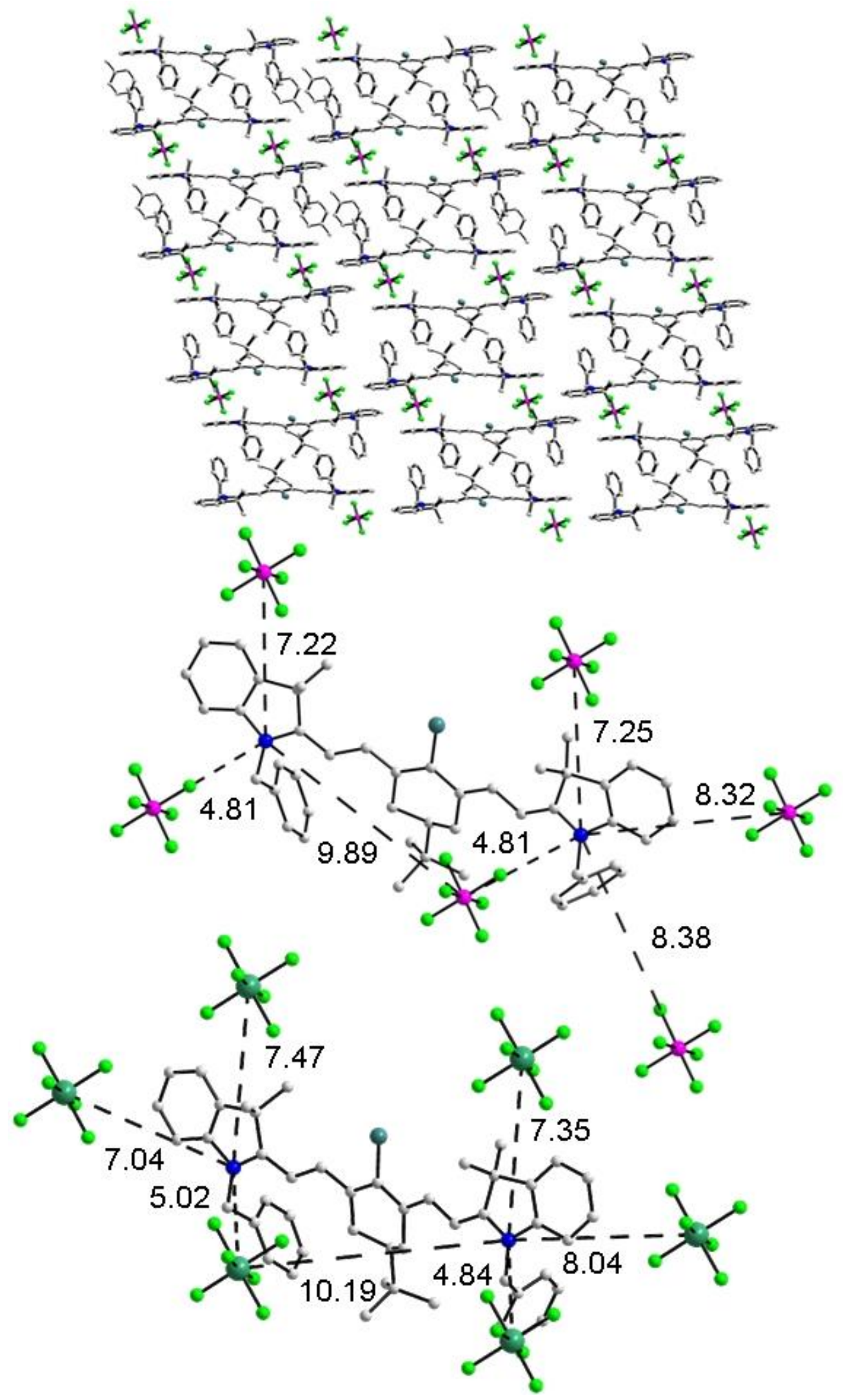

Figure 7. (up) View of the crystal packing of 1.[PF $]$ according to the $c$ axis. (bottom) Nearest anionic environment of the cyanine cation in the case of $\mathbf{1}$. $\left[\mathrm{PF}_{6}\right]$ (left) and $\mathbf{1}$. [ $\left.\mathrm{SbF}_{6}\right]$ (right). 


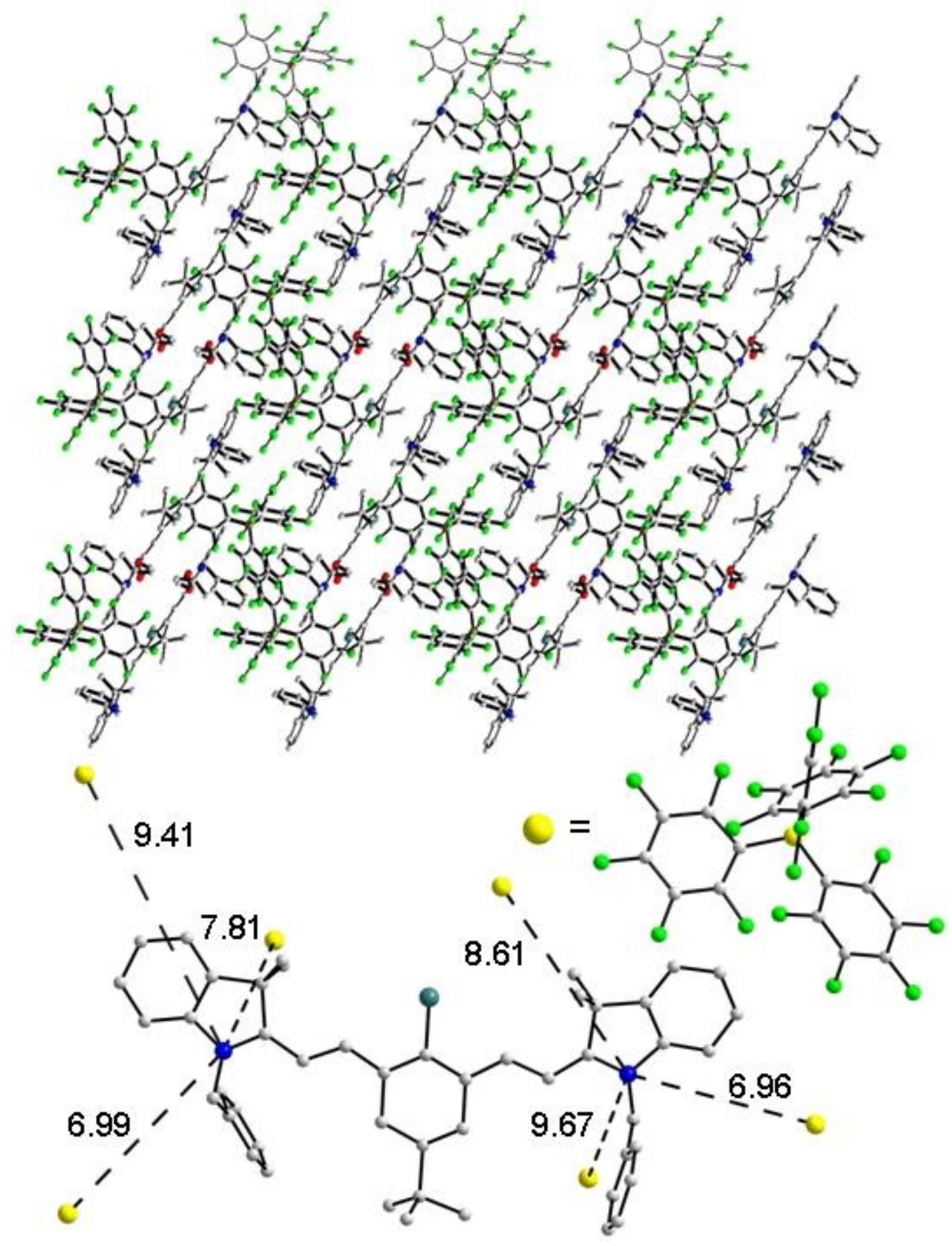

Figure 8. (up) View of the crystal packing of $1 .\left[\mathrm{B}\left(\mathrm{C}_{6} \mathrm{~F}_{5}\right)_{4}\right]$ according to the $c$ axis. (bottom) Nearest anionic environment of the cyanine cation in the case of $1 .\left[\mathrm{B}\left(\mathrm{C}_{6} \mathrm{~F}_{5}\right)_{4}\right]$. 


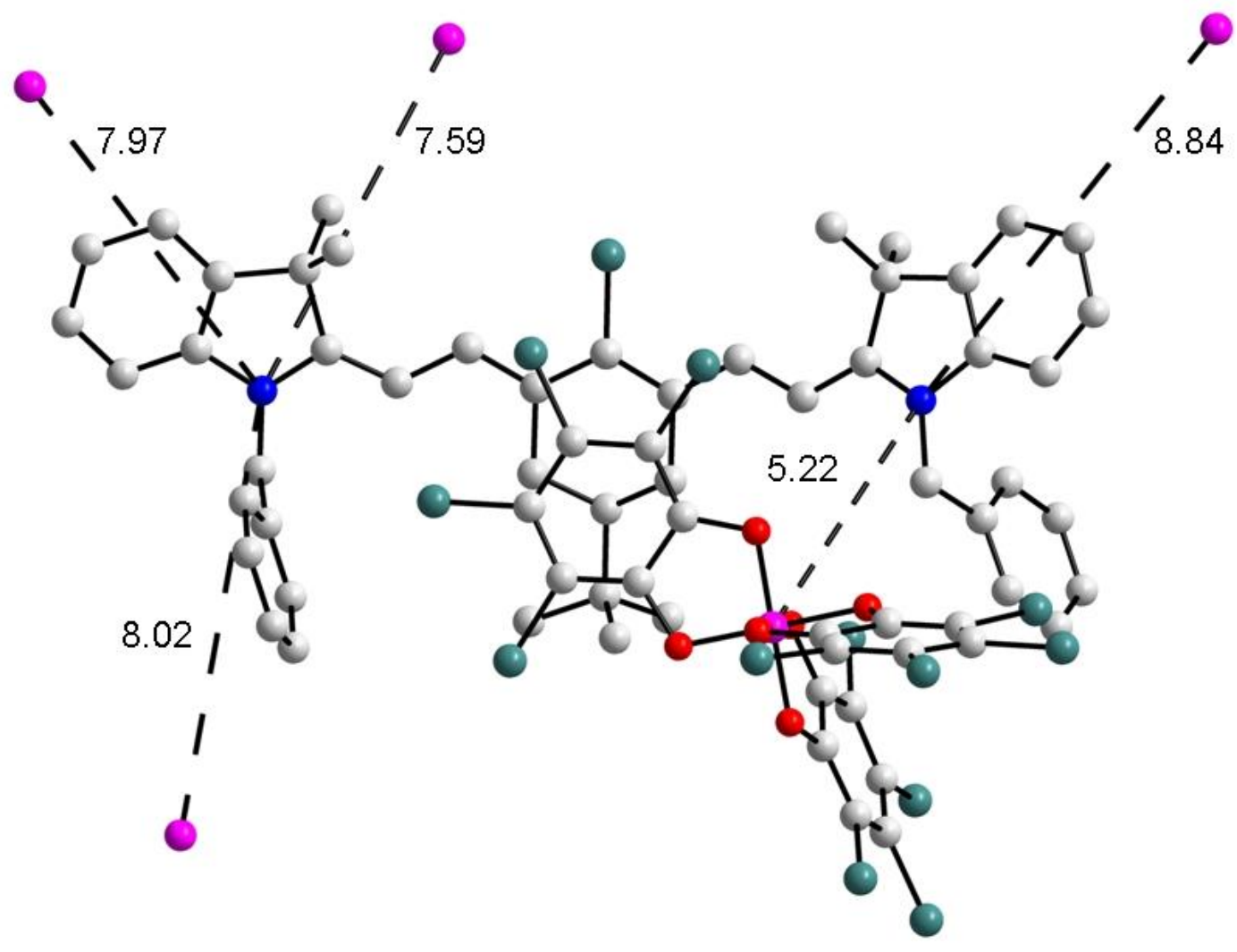

Figure 9. Nearest anionic environment of the cyanine cation in the case of 1.[TRISPHAT].

As a summary of this first part, it is noticeable that a given cyanine cation can generate very different structures in the solid state depending on the nature of the associated counteranion and on the symmetry of the anionic surrounding: a relatively small, hard anion, in a non symmetric environment is able to strongly polarize the polymethine chain resulting in a BLA comparable to that of related dipolar molecules. On the other hand, softer anion will not polarize significantly the conjugated chain whatever the symmetry of the packing. The same cyanine cation can therefore present two different structures in the solid state: a classical nonalternating IPS and a very scarce dipolar one. This clearly demonstrates that the electronic structure of the polymethine chain in the crystal may be tuned by anion/cation interactions in order to induce the crossing of the cyanine limit. 


\section{Absorption properties.}

The electrostatic interactions between anions and cations can also be controlled in solution by tuning the solvent polarity: whereas polar solvents will lead to the formation of dissociating solvated anions and cations, apolar solvents will favour associated ion-pairs. Therefore, the absorption properties of the different salts have been studied both in a non dissociated solvent, toluene featuring a very low dielectric constant $\left(\varepsilon_{\mathrm{r}}=1\right)$ and in a more polar one, dichloromethane ( $\left.\mathrm{DCM}, \varepsilon_{\mathrm{r}}=9\right)$. In dichloromethane, all cyanine salts present the same spectrum with a sharp absorption bandat $794 \mathrm{~nm}$ with giant extinction coefficient (300-

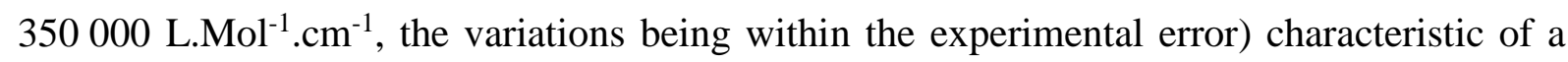
cyanine salt in its ideal polymethine state (Figure 9 up and Table 3).

On the contrary the different cyanine salts present completely different absorption spectra in toluene. Cyanine salts featuring bulky counter-anion like 1.[B( $\left.\left(\mathrm{C}_{6} \mathrm{~F}_{5}\right)_{4}\right]$ or 1.[TRISPHAT] conserve a similar spectrum than in dichloromethane indicating that the cyanine remains in the ideal polymethine state. In marked contrast, for $1 .[\mathrm{Br}]$ the sharp transition observed in DCM completely collapses in toluene $\left(\varepsilon=72000 \mathrm{~L}^{\mathrm{M}} \mathrm{Mol}^{-1} \cdot \mathrm{cm}^{-1}\right)$ whereas the higher energy shoulder seems to be less affected by the solvent modification. This profound modification of the absorption spectrum is continuous as illustrated by the series of spectra recorded in various dichloromethane-toluene mixtures (Figure 10). Importantly, the final spectrum of 1.[Br] in toluene presents a very similar shape than the spectrum of the neutral dipolar compound 2 recorded in DCM (Figure 10), ${ }^{20}$ suggesting that in toluene 1.[Br] is present under a dipolar form (Figure 5). This symmetry collapse is probably due to the asymmetric formation of an associated ion-pair between $\mathbf{1}^{+}$and $\mathrm{Br}^{-}$resulting in the polarization of the polymethine chain in agreement with the solid state structure featuring a large BLA (vide supra). The continuous transition from the IPS observed in dichloromethane to the dipolar 
state observed in toluene is simply driven by the thermodynamic solvation equilibrium between dissociated and associated ion pairs.

The other cyanine salts $1 .[\mathrm{I}], \mathbf{1} .\left[\mathrm{PF}_{6}\right]$ and $\mathbf{1} .\left[\mathrm{SbF}_{6}\right]$ exhibit an absorption spectrum in toluene intermediate between those of $\mathbf{1} .[\mathrm{Br}]$ and $\mathbf{1 .}\left[\mathrm{B}\left(\mathrm{C}_{6} \mathrm{~F}_{5}\right)_{4}\right]$ or 1.[TRISPHAT]. The sharp transition characteristic of IPS cyanine remains visible but is significantly attenuated with

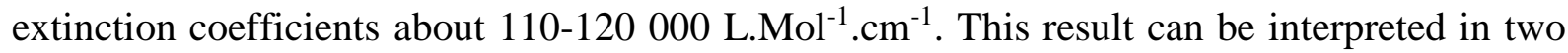
ways: (i) the thermodynamic solvation equilibrium is not fully displaced in favour of the associated or dissociated species, the two limit forms are present in solution in different amounts depending on the nature of the counter-anion and the experimental absorption spectrum results from their relative contribution. (ii) A single species is present in solution with its own absorption spectrum, but the polarisation of the polymethine chain, controlled by the interaction with the counter-anion is intermediate between the two limit forms. 

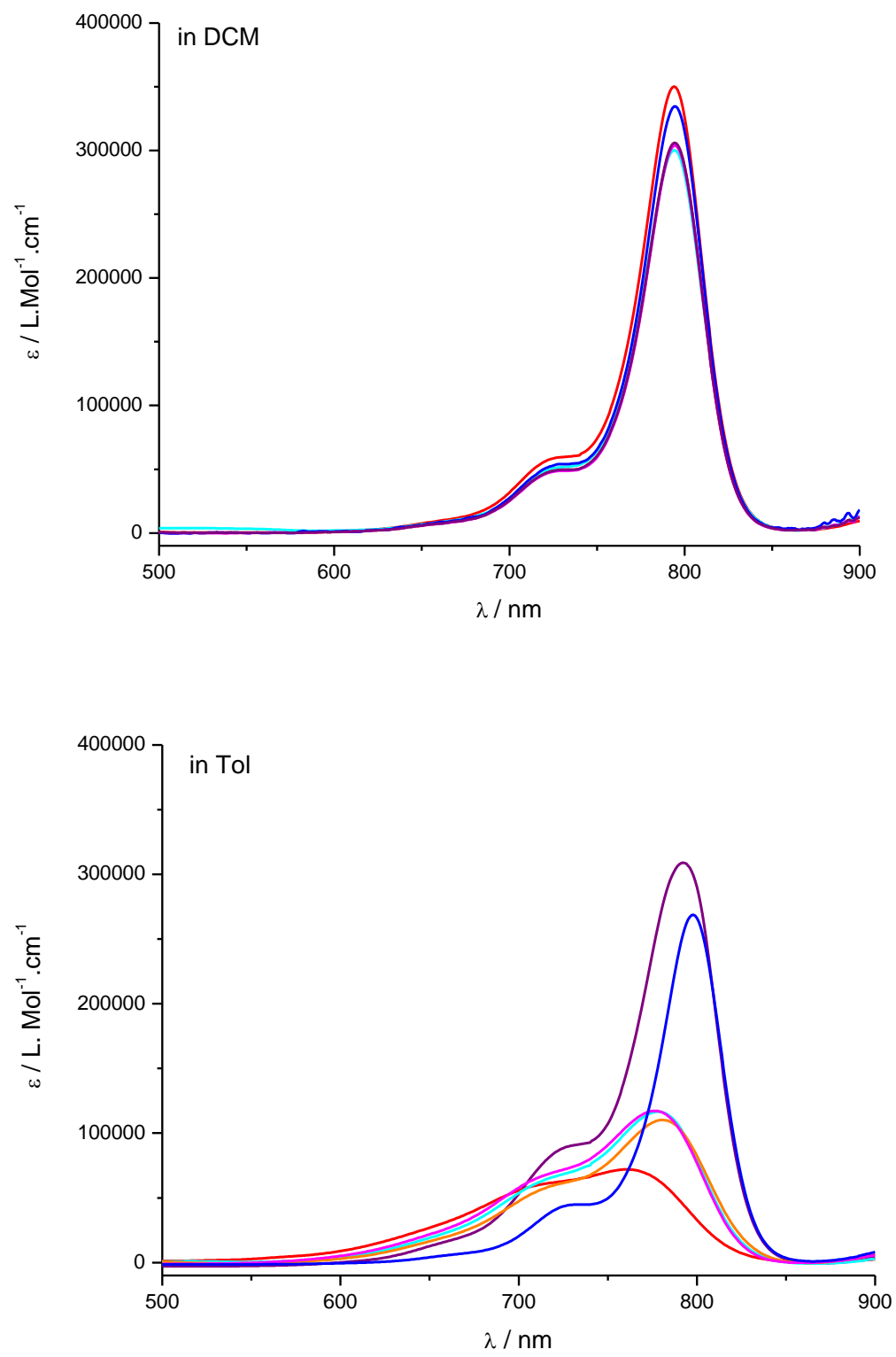

Figure 9. Absorption spectra of compounds 1.[TRISPHAT] (purple), 1.[B( $\left.\left.\mathrm{C}_{6} \mathrm{~F}_{5}\right)_{4}\right]$ (blue), 1. $\left[\mathrm{PF}_{6}\right]$ (cyan), 1.[SbF 6$]$ (magenta), 1.[I] (orange) and 1.[Br] (red) in DCM (up) and Tol (bottom). 


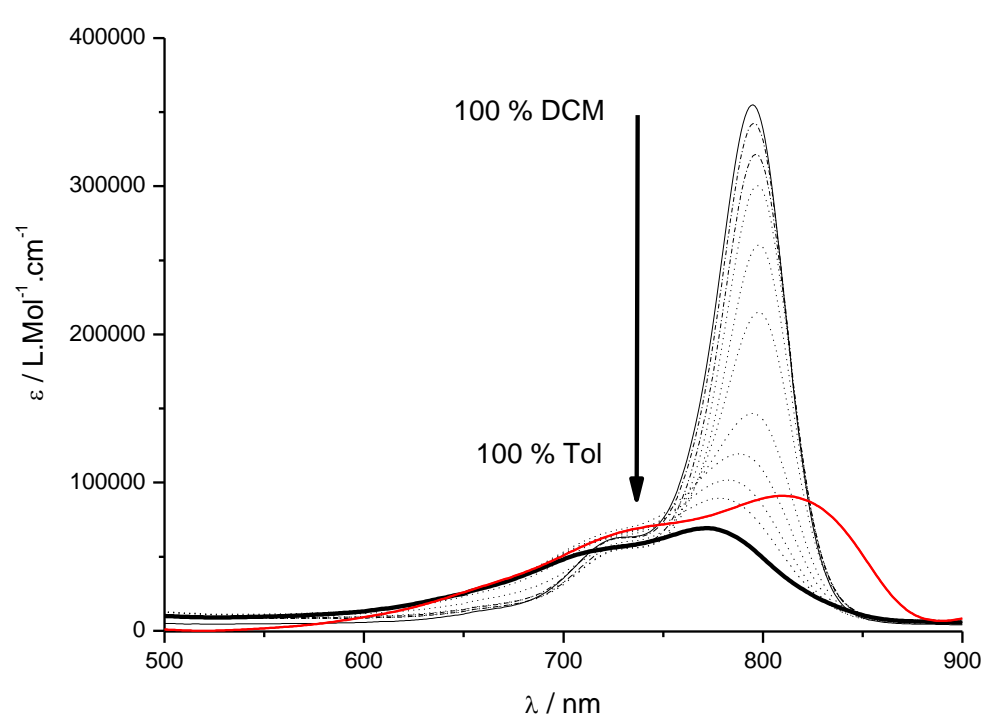

Figure 10. Variation of the absorption spectra of 1.[Br] in DCM/Tol solvent mixture, (thin) 100/0; (dotted) 90/10, 80/20, 70/30, 60/40, 50/50, 40/60, 30/70, 20/80, 10/90; (bold) 0/100. For comparison, the absorption spectrum of the dipolar compound 2 (red) in DCM was superimposed.

Table3. Photophysical data in DCM and in toluene

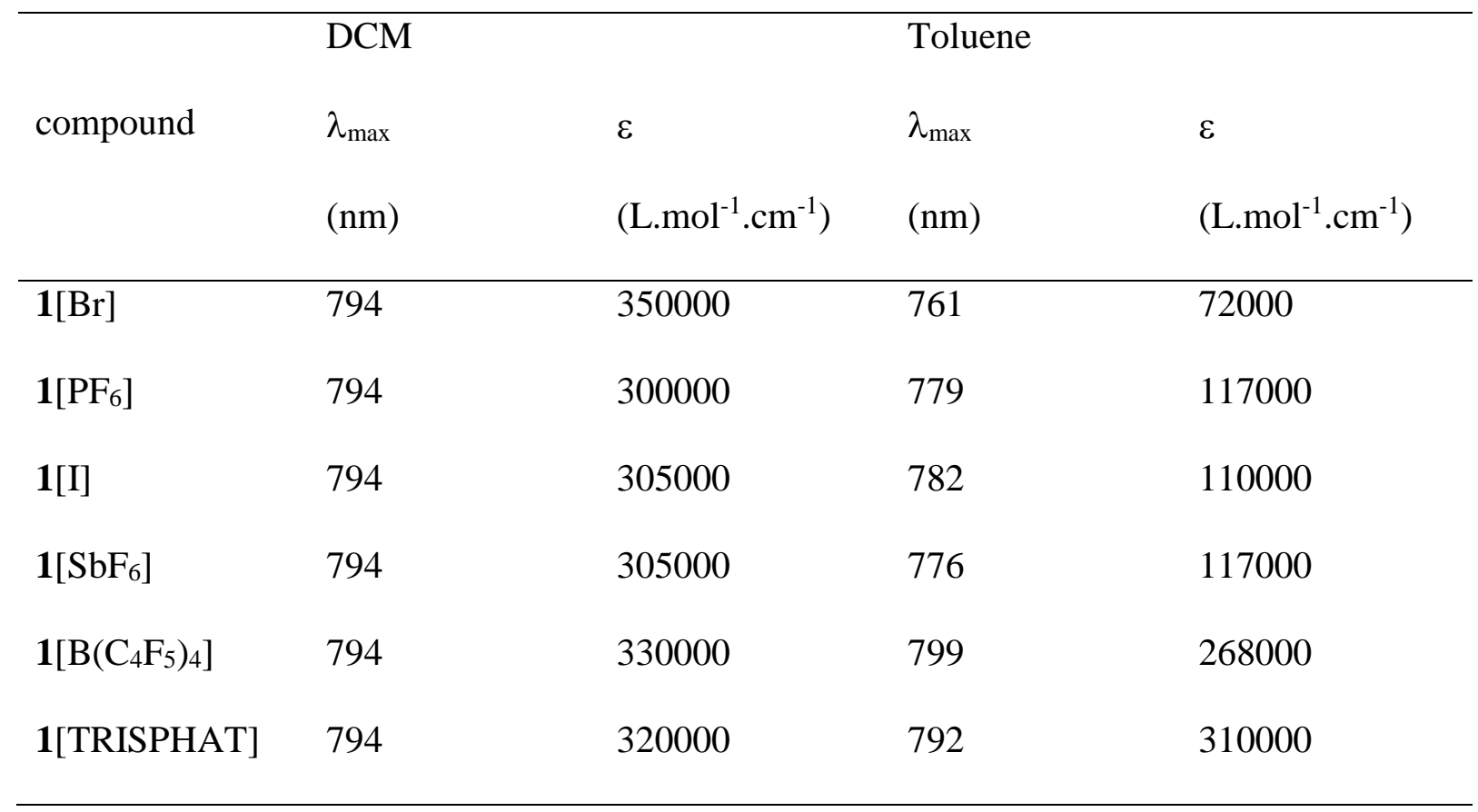




\section{Discussion.}

These experimental results are in line with the interpretation proposed by Lepkowicz, Hagan and co-workers ${ }^{15}$ However, these authors proposed that the cyanine cation should be present in its ground state in two charged forms with symmetrical and asymmetrical distribution of charge density. In fact, the cyanine cation alone can not present two different ground state structures and in such ambiguous situation the counter-anion must be taken into account for a more accurate description. In the light of the above-mentioned results, a more accurate description can be proposed: the anion-cyanine couple exists in solution under two different forms: (i) an intimate ion pair or (ii) a dissociated ion pair in a more polar solvent. The dissociated ion pair presents always the structural and electronic properties of the cyanine cation in its ideal polymethine state whatever the nature of the anion. In the case of associated ion pair two cases must be envisaged: if the counter-ion is soft according to the HSAB classification, the cyanine will conserve its IPS structure. On the contrary, a hard anion will localised the positive charge on one side of the polymethine chain resulting in the formation of asymmetrical dipolar structures featuring very different absorption properties.

Furthermore, these results can be generalized to the field of material science were polymer or sol-gel matrices doped with cyanine dyes are widely used for photovoltaic or nonlinear optical applications. ${ }^{3 a, 3 f}$ As example, the Figure 11 describes the absorption spectra of two polymethylmethachrylate thin films spin coated on glass plates and doped with XX weight \% of $\mathbf{1}[\mathrm{Br}]$ and $\mathbf{1}[\mathrm{TRISPHAT}]$. The shapes of the normalized spectra are very different; in particular the sharp transition of the cyanines in their ideal polymethyne states is conserved in the case of the TRISPHAT salts but almost completely disappears for the bromide one. In such materials, the electronic structure of the cyanine cation can therefore be controlled by the interactions with its counter-anion as already observed in the crystal and in solution. 


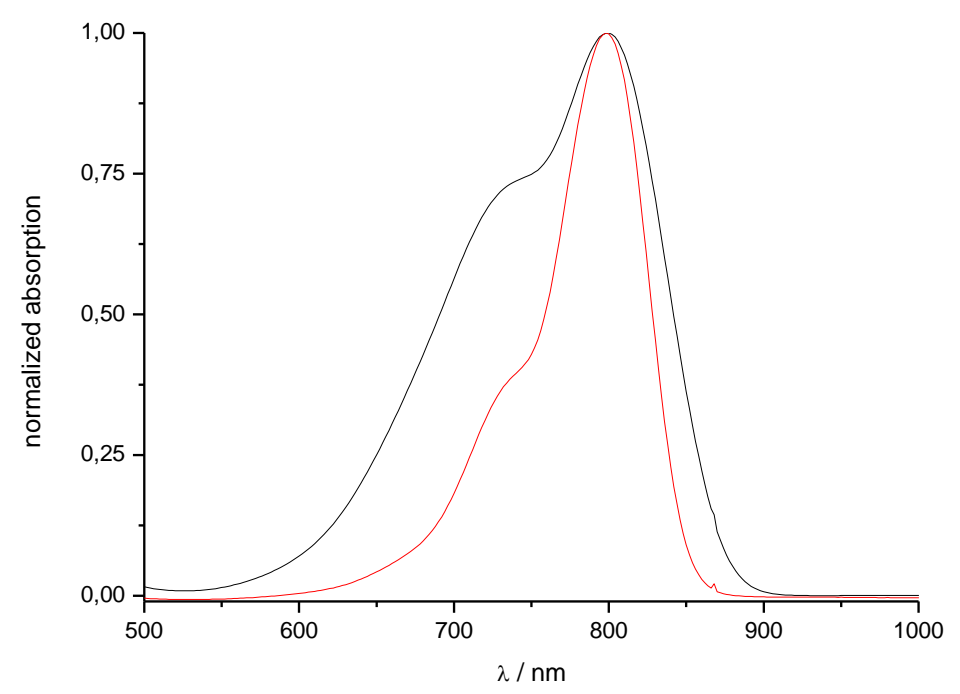

Figure 11. Normalized absorption spectra of PMMA thin film doped with 1.[Br] (black) and 1.[TRISPHAT] (red).

\section{Conclusion.}

In this article we emphasised the very important role of the counter-anion on the structural and electronic properties of heptamethine cyanine cation. We unambiguously demonstrated that a small, hard anion (bromide) is able to strongly polarise the polymethyne chain resulting in the stabilisation of asymmetric dipolar-like structure in the crystal and in non dissociating solvent. On the contrary, in more polar solvent or associated with bulky soft anion (TRISPHAT or $\left.\mathrm{B}\left(\mathrm{C}_{6} \mathrm{~F}_{5}\right)_{4}^{-}\right)$, the same cyanine dye adopts preferentially the ideal polymethine state. For the best of our knowledge, it is the very first time that the same cyanine structure is isolated under its two limit forms, a symmetric and a dipolar one, both in solution and in the solid state, simply by playing with the nature of the counter-anion or with the solvent polarity. This result is important from a fundamental point of view, because the role of the counter- 
anion neglected up to now, can participate to the explanation of many absorption properties modifications induced by the solvent or by interactions with exogenous molecules even biomacromolecules. In addition, we demonstrated that the nature of the counter-anion is also able to control the absorption spectrum of cyanine cation used as dopant in polymeric matrix. In conclusion, the modulation of the structural and electronic properties of cyanine cations by interaction with the counter-anion is a general phenomenon observed in the crystal, in solution and in polymeric matrix. In the future, counter-ions effects have to be considered as important parameter for the design of new cyanine dyes or new cyanine-based applications.

\section{Experimental Section.}

General. All reactions were routinely performed under argon. NMR spectra $\left({ }^{1} \mathrm{H},{ }^{13} \mathrm{C}\right)$ were recorded at room temperature on a BRUKER AC 200 operating at $200.13 \mathrm{MHz}$ and 50.32 for ${ }^{1} \mathrm{H}$ and ${ }^{13} \mathrm{C}$ respectively. Data are listed in parts per million (ppm) and are reported relative to tetramethylsilane $\left({ }^{1} \mathrm{H},{ }^{13} \mathrm{C}\right)$, residual solvent peaks being used as internal standard $\left(\mathrm{CHCl}_{3}{ }^{1} \mathrm{H}\right.$ : $\left.7.26 \mathrm{ppm},{ }^{13} \mathrm{C}: 77.36 \mathrm{ppm}\right)$. UV-visible spectra were recorded on a Jasco V-550 spectrophotometer in diluted solution $\left(c a .10^{-5}\right.$ mol.L $\left.\mathrm{L}^{-1}\right)$. High resolution mass spectrometry measurements and elemental analysis were performed at the Service Central d'Analayse du CNRS (Vernaison, France). Column Chromatography was performed on Merck Gerduran 60 $(40-63 \mu \mathrm{m})$ silica. The synthesis of $\mathbf{1}[\mathrm{Br}]$ and $\mathbf{1}[\mathrm{D}-\mathrm{TRISPHAT}]^{21}$ have been reported elsewhere.

Computational details. DFT geometry optimizations on $\mathbf{2}^{-}$, model of $\mathbf{2}^{-}$with the tert-butyl fragment replaced by a Me group, were carried out with the Gaussian 03 (Revision B.04) package $^{22}$ employing the three-parameter hybrid functional of Becke based on the correlation 
functional of Lee, Yang, and Parr (B3LYP). ${ }^{23,24}$ The 6-31G* basis sets were used for C, N, and $\mathrm{H}$ atoms, whereas a diffuse function was added for $\mathrm{O}$ and $\mathrm{Cl}$.

\section{X-ray crystallography.}

Data collection: For compounds Pab101, Pab1602, Pab285, Pab160-renum, Pab1603p, processing of the data was performed by the Oxford Diffraction Xcalibur Saphir 3 diffractometer analysis softwares (Crysalis, 2004). The lattice constants were refined by leastsquare refinement using 2471 reflections $\left(2.7^{\circ}<\theta<32^{\circ}\right) ; 3197\left(2.6^{\circ}<\theta<27^{\circ}\right), 6413\left(2.6^{\circ}<\right.$ $\left.\theta<32^{\circ}\right), 3781\left(2.8^{\circ}<\theta<32^{\circ}\right), 6655\left(2.7^{\circ}<\theta<32^{\circ}\right)$ respectively. No absorption correction was applied to data sets.

Structure solution and refinement: Pab285, Pab160-renum, Pab1603p crystallize in the triclinic system and according to the observed systematic extinctions, the structures have been solved in the $P-1$ space group (No. 2). Pab101, Pab1602 crystallize in the monoclinic system and according to the observed systematic extinctions, the structures have been solved in the $P 2 / c$ space group (No. 14).

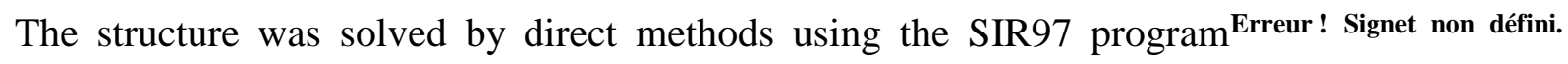
combined to Fourier difference syntheses and refined against $F$ square using reflections with $[I / \sigma(I)>2]$ with SHELXL97. ${ }^{25}$ All atomic displacements parameters for non-hydrogen atoms have been refined with anisotropic terms. After anisotropic refinement, all the hydrogen atoms are found with a Fourier Difference. Table 1 summarizes the crystallographic data and refinement details for Pab101, Pab1602, Pab285, Pab160-renum, Pab1603p.

$\mathbf{1}[\mathrm{I}] \quad \mathbf{1}\left[\mathrm{PF}_{6}\right] \quad \mathbf{1}\left[\mathrm{SbF}_{6}\right] \quad \mathbf{1}\left[\mathrm{B}_{\left.\left(\mathrm{C}_{6} \mathrm{~F}_{5}\right)_{4}\right]} \mathbf{1}[\right.$ TRISPHAT $]$

Table 2. Crystal data and structure refinement parameters.

\begin{tabular}{llllll}
\hline & Pab101 & Pab1602 & Pab285 & Pab160-renum & Pab1603p \\
\hline Formula & $\mathrm{C}_{48} \mathrm{H}_{52} \mathrm{BrClN}_{2}$ & $\mathrm{C}_{48} \mathrm{H}_{52} \mathrm{ClIN}_{2}$ & $\mathrm{C}_{72.50} \mathrm{H}_{54} \mathrm{BClF}_{20} \mathrm{~N}$ & $\mathrm{C}_{58.50} \mathrm{H}_{64} \mathrm{ClF}_{6} \mathrm{~N}_{2} \mathrm{P}$ & $\mathrm{C}_{55} \mathrm{H}_{60} \mathrm{ClF}_{6} \mathrm{~N}_{2} \mathrm{Sb}$ \\
& & & & & \\
& & & &
\end{tabular}




\begin{tabular}{|c|c|c|c|c|c|}
\hline f.w. (g.mol $\left.{ }^{-1}\right)$ & 772.28 & 819.27 & 1415.46 & 975.54 & 1020.25 \\
\hline Cryst. Syst. & Monoclinic & Monoclinic & Triclinic & Triclinic & Triclinic \\
\hline Space group & $P 2_{1} / c($ No. 14$)$ & $P{ }_{1} / c$ (No. 14) & $P-1$ (No. 2) & $P-1$ (No. 2) & $P-1$ (No. 2) \\
\hline $\mathrm{a}(\AA)$ & $12.676(7)$ & $12.473(1)$ & $13.237(7)$ & $9.665(7)$ & $10.023(6)$ \\
\hline $\mathrm{b}(\AA)$ & $19.587(9)$ & $19.634(1)$ & $14.661(8)$ & $14.125(1)$ & $15.406(9)$ \\
\hline$c(\AA)$ & $17.606(8)$ & $17.670(1)$ & $17.009(8)$ & $20.717(1)$ & $18.064(9)$ \\
\hline$\alpha\left(^{\circ}\right)$ & 90.0 & 90.0 & 84.837 (4) & $75.156(6)$ & $67.377(6)$ \\
\hline$\beta\left({ }^{\circ}\right)$ & $103.143(5)$ & $103.098(3)$ & $85.032(4)$ & $87.153(6)$ & $83.711(5)$ \\
\hline$\gamma\left(\left(^{\circ}\right)\right.$ & 90.0 & 90.0 & $81.250(5)$ & $69.688(7)$ & $77.485(5)$ \\
\hline $\mathrm{V}\left(\AA^{3}\right)$ & $4256.7(4)$ & 4214.9 (3) & $3240.3(3)$ & $2561.4(3)$ & $2512.4(2)$ \\
\hline Z & 4 & 4 & 2 & 2 & 2 \\
\hline $\mathrm{T}(\mathrm{K})$ & 295 & 110 & 110 & 110 & 110 \\
\hline$\lambda(\operatorname{MoK} \alpha)(\AA)$ & 0.71069 & 0.71069 & 0.71069 & 0.71069 & 0.71069 \\
\hline $\mathrm{D}\left(\mathrm{g} \cdot \mathrm{cm}^{-3}\right)$ & 1.205 & 1.291 & 1.451 & 1.265 & 1.349 \\
\hline$\mu\left(\mathrm{mm}^{-1}\right)$ & 1.06 & 0.86 & 0.17 & 0.17 & 0.66 \\
\hline $\mathrm{R}(\mathrm{F})^{\mathrm{a}}$ & 0.073 & 0.061 & 0.064 & 0.051 & 0.058 \\
\hline $\mathrm{R}_{\mathrm{w}}\left(\mathrm{F}^{2}\right)^{\mathrm{b}}$ & 0.279 & 0.176 & 0.193 & 0.131 & 0.170 \\
\hline S & 0.67 & 0.80 & 0.86 & 0.65 & 0.77 \\
\hline Rint & 0.056 & 0.069 & 0.032 & 0.057 & 0.035 \\
\hline$\theta \max$ & $28.0^{\circ}$ & $27.0^{\circ}$ & $32.2^{\circ}$ & $32.0^{\circ}$ & $32.0^{\circ}$ \\
\hline $\mathrm{h}$ & $-16 \rightarrow 15$ & $-15 \rightarrow 15$ & $-19 \rightarrow 15$ & $-6 \rightarrow 14$ & $-6 \rightarrow 14$ \\
\hline $\mathrm{k}$ & $-22 \rightarrow 25$ & $-25 \rightarrow 25$ & $-17 \rightarrow 21$ & $-20 \rightarrow 20$ & $-22 \rightarrow 22$ \\
\hline 1 & $-23 \rightarrow 23$ & $-22 \rightarrow 16$ & $-25 \rightarrow 23$ & $-29 \rightarrow 30$ & $-26 \rightarrow 26$ \\
\hline Parameters & 451 & 469 & 878 & 640 & 614 \\
\hline Measured & 27204 & 29286 & 26729 & 21313 & 21602 \\
\hline $\begin{array}{l}\text { reflections } \\
\text { Independent }\end{array}$ & 9784 & 9147 & 16798 & 13603 & 13897 \\
\hline Reflections & 2471 & 3197 & 6413 & 3781 & 6659 \\
\hline$\Delta \rho_{\min }$ & -0.33 e $\AA^{-1}$ & -0.96 & -0.51 & -0.29 e $\AA^{-1}$ & -1.05 e $\AA^{-1}$ \\
\hline$\Delta \rho_{\max }$ & 0.91 e $\AA^{-1}$ & 1.23 & 0.85 & $0.38 \mathrm{e} \AA^{-1}$ & $1.17 \mathrm{e} \AA^{-1}$ \\
\hline
\end{tabular}

1. $\left[\mathrm{PF}_{6}\right]$. (Method A) 1.[Br] (1 eq.) is dissolved in the minimal amount of methanol. This solution is added drop wise to an aqueous solution of sodium hexafluorophosphate (50 eq.) under violent stirring. The resulting precipitate is filtered and the crude is dissolved in DCM 
and the solution is extracted with water $(3 \times 15 \mathrm{~mL})$, filtrated trough a silica plug (washed with DCM). Then the solvents were evaporated to afford a green solid (86 $\mathrm{mg}, 80 \%)$. Single crystals suitable for X-rays diffraction analysis were obtained by slow evaporation of chloroform-toluene mixture. ${ }^{1} \mathrm{H} \mathrm{NMR}\left(200.13 \mathrm{MHz}, \mathrm{CDCl}_{3}\right): \delta 0.95(\mathrm{~s}, 9 \mathrm{H}), 1.4(\mathrm{~m}, 1 \mathrm{H}), 1.72$ (s, 6H), $1.74(\mathrm{~s}, 6 \mathrm{H}), 2.00\left(\mathrm{dd},{ }^{3} J=13 \mathrm{~Hz},{ }^{2} J=13 \mathrm{~Hz}, 2 \mathrm{H}\right), 2.57\left(\mathrm{dd},{ }^{3} J=2 \mathrm{~Hz},{ }^{2} J=13 \mathrm{~Hz}\right.$, 2H), $5.28(\mathrm{~s}, 4 \mathrm{H}), 6.07\left(\mathrm{~d},{ }^{3} \mathrm{~J}=14 \mathrm{~Hz}, 2 \mathrm{H}\right), 7.2-7.5(\mathrm{~m}, 18 \mathrm{H}), 8.23\left(\mathrm{~d},{ }^{3} \mathrm{~J}=14 \mathrm{~Hz}, 2 \mathrm{H}\right) .{ }^{13} \mathrm{C}$ NMR (50.32 MHz, $\left.\mathrm{CDCl}_{3}\right): \delta$ 27.3, 28.1, 28.2, 32.3, 42.0, 48.1, 49.3, 102.2, 110.9, 122.5, 125.6, 126.6, 128.4, 129.0, 129.2, 134.2, 140.9, 142.8, 144.4, 150.8, 172.6. ${ }^{31} \mathrm{P}$ NMR (81 $\left.\mathrm{MHz}, \mathrm{CDCl}_{3}\right): \delta$ 174.2. Anal. calcd for $\mathrm{C}_{48} \mathrm{H}_{52} \mathrm{~N}_{2} \mathrm{ClF}_{6} \mathrm{P} \cdot \mathrm{H}_{2} 0: \mathrm{C}, 67.40, \mathrm{H}, 6.36, \mathrm{~N}, 3.27$, Found $\mathrm{C}, 67.77, \mathrm{H}, 6.32, \mathrm{~N}, 3.20 . \mathrm{UV}-\mathrm{Vis}\left(\mathrm{CH}_{2} \mathrm{Cl}_{2}\right): \lambda_{\max }=794 \mathrm{~nm}\left(\varepsilon_{\max }=290000 \mathrm{~L} \cdot \mathrm{mol}^{-1} \cdot \mathrm{cm}^{-1}\right)$.

1. $\left[\mathrm{SbF}_{6}\right]$ is synthesized using Method A from 1.[Br] with $[\mathrm{Na}]\left[\mathrm{SbF}_{6}\right]$. Single crystals suitable for X-rays diffraction analysis were obtained by slow evaporation of chloroform-toluene mixture. ${ }^{1} \mathrm{H}$ NMR (200.13 MHz, $\left.\mathrm{CDCl}_{3}\right): \delta 0.95(\mathrm{~s}, 9 \mathrm{H}), 1.40(\mathrm{~m}, 1 \mathrm{H}), 1.72(\mathrm{~s}, 6 \mathrm{H}), 1.74(\mathrm{~s}$, $6 \mathrm{H}), 2.00\left(\mathrm{dd},{ }^{3} J=13 \mathrm{~Hz},{ }^{2} J=13 \mathrm{~Hz}, 2 \mathrm{H}\right), 2.58\left(\mathrm{dd},{ }^{3} J=2 \mathrm{~Hz},{ }^{2} J=13 \mathrm{~Hz}, 2 \mathrm{H}\right), 5.30(\mathrm{~s}, 4 \mathrm{H})$, $6.09\left(\mathrm{~d},{ }^{3} J=14 \mathrm{~Hz}, 2 \mathrm{H}\right), 7.2-7.5(\mathrm{~m}, 18 \mathrm{H}), 8.23\left(\mathrm{~d},{ }^{3} \mathrm{~J}=14 \mathrm{~Hz}, 2 \mathrm{H}\right)$. Anal. calcd for $\mathrm{C}_{48} \mathrm{H}_{52} \mathrm{~N}_{2} \mathrm{ClF}_{6} \mathrm{Sb}: \mathrm{C}, 62.11, \mathrm{H}$, 5.65, N, 3.02, Found C, 62.01, H, 5.91, N, 2.90.

1.[I] is synthesized using Method A from 1.[Br] with $[\mathrm{Na}][\mathrm{I}]$. Single crystals suitable for $\mathrm{X}-$ rays diffraction analysis were obtained by slow evaporation of chloroform-toluene mixture. ${ }^{1} \mathrm{H}$ NMR (200.13 MHz, CDCl 3 ): $\delta 0.97$ (s, 9H), $1.4(\mathrm{~m}, 1 \mathrm{H}), 1.73(\mathrm{~s}, 6 \mathrm{H}), 1.75(\mathrm{~s}, 6 \mathrm{H}), 2.07$ $\left(\mathrm{dd},{ }^{3} J=13 \mathrm{~Hz},{ }^{2} J=13 \mathrm{~Hz}, 2 \mathrm{H}\right), 2.57\left(\mathrm{dd},{ }^{3} J=2 \mathrm{~Hz},{ }^{2} J=13 \mathrm{~Hz}, 2 \mathrm{H}\right), 5.40\left(\mathrm{~d},{ }^{2} J=16 \mathrm{~Hz}\right.$, 2H), $5.52\left(\mathrm{~d},{ }^{2} J=16 \mathrm{~Hz}, 2 \mathrm{H}\right), 6.17\left(\mathrm{~d},{ }^{3} J=14 \mathrm{~Hz}, 2 \mathrm{H}\right), 7.2-7.5(\mathrm{~m}, 18 \mathrm{H}), 8.21\left(\mathrm{~d},{ }^{3} J=14 \mathrm{~Hz}\right.$, $2 \mathrm{H})$.

1. $\left[\mathrm{B}\left(\mathrm{C}_{6} \mathrm{~F}_{5}\right)_{4}\right]$. (Method B) 1.[Br] (50 mg, $0.06 \mathrm{mmol}, 1$ eq.) was dissolved in DCM (10 mL). Lithium tetrakis(pentafluorophenyl)borate ethyletherate $(56 \mathrm{mg}, 1$ eq.) was added and the solution was stirred $30 \mathrm{~min}$ at RT. The solution was washed with water ( $3 \times 15 \mathrm{~mL})$, filtrated 
trough a silica plug (washed with DCM). Then the solvents were evaporated to afford a green solid. Single crystals suitable for X-rays diffraction analysis were obtained by slow evaporation of chloroform-methanol mixture. ${ }^{1} \mathrm{H}$ NMR $\left(200.13 \mathrm{MHz}, \mathrm{CDCl}_{3}\right): \delta 0.89(\mathrm{~s}, 9 \mathrm{H})$, $1.35(\mathrm{~m}, 1 \mathrm{H}), 1.69(\mathrm{~s}, 12 \mathrm{H}), 1.91\left(\mathrm{dd},{ }^{3} J=13 \mathrm{~Hz},{ }^{2} J=13 \mathrm{~Hz}, 2 \mathrm{H}\right), 2.53\left(\mathrm{dd},{ }^{3} J=2 \mathrm{~Hz},{ }^{2} J=13\right.$ $\mathrm{Hz}, 2 \mathrm{H}), 5.08\left(\mathrm{~d},{ }^{2} J=16 \mathrm{~Hz}, 2 \mathrm{H}\right), 5.20\left(\mathrm{~d},{ }^{2} J=16 \mathrm{~Hz}, 2 \mathrm{H}\right), 5.98\left(\mathrm{~d},{ }^{3} J=14 \mathrm{~Hz}, 2 \mathrm{H}\right), 7.2-7.5$ (m, $18 \mathrm{H}), 8.27\left(\mathrm{~d},{ }^{3} \mathrm{~J}=14 \mathrm{~Hz}, 2 \mathrm{H}\right)$. Anal. calcd for $\mathrm{C}_{72} \mathrm{H}_{52} \mathrm{~N}_{2} \mathrm{ClBF}_{20}: \mathrm{C}, 63.06, \mathrm{H}, 3.82, \mathrm{~N}$, 2.04, Found C, 63.42, H, 3.76, N, 2.28.

Acknowledgment. Authors thank the Direction Générale de l'Armement for a grant to PAB. The authors are also Grateful to Pr. S. Parola (university of Lyon) for the preparation of polymer thin films.

\section{References and notes.}

$\dagger$ University of Lyon

† University of Rennes

1 This article is a complementary study to the benchmark paper of Tolbert et al. entitled "Beyond the Cyanine Limit: Peierls Distortion and Symmetry Collapse in Polymethine Dyes" Tolbert, L.M.; Zhao, X. J. Am. Chem. Soc., 1997, 119, 3253-3258.

2 For reviews see: Kulinich, A. V.; Ishchenko, A.A. Russ. Chem. Rev., 2009, 78, 141-162; Mishra, A.; Behera, R. K.; Behera, P. K.; Mishra, B. K.; Behera, G. B. Chem. Rev. 2000, 100, 1973-2011; Fabian, J. Chem. Rev. 1992, 92, 1197-1226.

3 For selected recent examples see: a) Bouit, P.-A.; Rauh, D.; Neugebauer, S.; Delgado, J.- L.; Di Piazza, E.; Rigaut, S.; Maury, O.; Andraud, C.; Dyakonov, V.; Martin N. Org. Lett. 2009, accepted; b) Silvestri, F.; Irwin, M. D.; Beverina, L. ; Facchetti, A. ; Pagani, G. A. ; Marks T. J. J. Am. Chem. Soc 2009, 130, 17640-17641; c) Bouit, P.-A.; Westlund, R.; Feneyrou, P.; 
Maury, O.; Malkoch, M.; Malmström, E.; Andraud, C. New J. Chem. 2009, 33, 964-968; d) Kronenberg, N. M. ; Deppish, M. ; Würthner, F. ; Lademann, H. V. A. ; Deing K. Meerholz, K. Chem. Commun. 2008, 6489-6491; e) Bouit, P.-A.; Wetzel, G.; Berginc, G.; Toupet, L.; Feneyrou, P.; Bretonnière, Y.; Maury, O.; Andraud, C. Chem. Mater. 2007, 19, 5325-5335; f)

Hales, J. M.; Zheng, S.; Barlow, S.; Marder, S. R.; Perry J. J. Am. Chem. Soc. 2006, 128, 11362-11363.

4 For selected recent examples see: Kundu, K. Knight, S.F. Willett, N.; Lee, S.; Taylor, W.R. Murthy, N. Angew. Chem. Int. Ed. 2009, 48, 299-303; Kim, E.-M.; Park, E.-H.; Cheong, S.-J.; Lee, C.-M.; Jeong, H.-J.; Kim, D. W.; Lim, S. T.; Sohn, M.-H. Biconjugate Chem., 2009, 20, 1299-1306.

5 Dähne, S. ; Radeglia, R. Tetrahedron, 1971, 27, 3673-3696.

6 The BLA parameter, also called Bonds Order Alternation (BOA) was emphasized by Marder to rationnalized empirically the second order nonlinear optical activity of push-pull dyes. See: a) Bourhill, G., Brédas, J. L.; Cheng, L.T.; Marder, S. R.; Meyers, F.; Perry, J. W.; Tiemann, B. G. J. Am. Chem. Soc., 1994, 116, 2619-2620; b) Marder, S. R. ; Kippelen, B.; Jen A. K.-Y.; Peyghambarian N. Nature, 1997, 388, 845-851.

7 Rettig, W.; Dekhtyar Chem. Phys., 2003, 293, 75-90; b) Ishchenko, A.A., Kulinich, A.V.; Bondarev, S.L. Knyukshto, V.N. J. Phys. Chem. A 2007, 111, 13629-13627.

8 a) Lawrentz, U.; Grahn, W.; Lukaszuk, K. Klein, C.; Wortmann, R.; Feldner, A.; Scherer, D. Chem. Eur. J., 2002, 8, 1573-1587; b) Würthner, F. ; Archetti G.; Schmidt, R.; Kuball, H.G. Angew. Chem. Int. Ed. 2008, 47, 4529-4532; c) Kulinich, A.V.; Derevyanko, N.A. Ishchenko, A.A., Bondarev, S.L. Knyukshto, V.N. J. Photochem. Photobiol. A : Chem. 2008, 200, 106-113.

9 For several recent examples see : a) Bouit, P.-A.; Di Piazza, E.; Rigaut, S.; Le Guennic, B.; Aronica, C.; Toupet, L.; Andraud, C.; Maury, O. Org. Lett., 2008, 10, 4159-4162 
10 b) Yau, C.M.S.; Pascu, S. I.; Odom, S.A.; Warren, J.E.; Koltz, E.J.F.; Frampton, M.J.; Williams, C.C.; Coropceanu, V.; Kuimova, M.K.; Phillips, D.; Barlow, S.; Brédas, J.-L.; Marder, S.R.; Millar, V.; Anderson, H. L. Chem. Commun. 2008, 2897-2899; Nagao, Y.; Sakai, T.; Kozawa, K.; Urano, T. Dyes Pigm. 2007, 73, 344-352; c) Dai, Z.F.; Peng, B.X.; Chen, X.A. Dyes Pigm. 1999, 40, 219-223; d) Koska, N.A. ; Wilson, S.R. ; Schuster, G.B. J. Am. Chem. Soc. 1993, 115, 11628-11629 ; e) Kulpe, S.; Kuban, R. J.; Schulz, B.; Dähne, S. Cryst. Res. Technol. 1987, 22, 375-379.

11 Egorov, V.V. J. Chem. Phys., 2002, 116, 3090-3102; Kachkovsky, O.D., Shut, D.M. Dyes Pigm. 2006, 71, 19-27; Guillaume, M.; Liégeois, V.; Champagne, B.; Zutterman, F. Chem. Phys. Lett. 2007, 446, 165-169;

12 Kachkovski, O.D.; Tolmachov, O.I. ; Slominskii, Y.L. ; Kudinova, M.O.; Derevyanko, N.O. ; Zhukova, O.O. Dyes Pigm. 2005, 64, 207-216 and references therein.

13 Brooker, L.G.S. ; Sprague, R.H. Smyth, C.P. ; Lewis, G.L. J. Am. Chem. Soc., 1940, 62, $1116-1125$.

14 J. Fabian, J. Mol. Struct. THEOCHEM, 2006, 766, 49-60.

15 Lepkowicz, R.S. ; Przhonska, O.V. ; Hales, J.M. ; Fu, J. ; Hagan, D.J.; Van Stryland, E.W.; Bondar, M.V.; Slominsky, Y.L. Kachkovski, A.D. CHem. Phys., 2004, 305, 259-270.

16 Barlow, S. ; Henling L.M.; Day, M.W.; Marder, S.R. Chem. Commun. 1999, 1567-1568.

${ }^{17}$ a) Owen, D. J.; Schuster, G. B. J. Am. Chem. Soc. 1996, 188, 259-256. b) Owen, D. J.; Van Derveer, D.; Schuster, G. B. J. Am. Chem. Soc. 1998, 120, 1705-1717.

18 Bouit, P.-A.; Aronica, C.; Guy, L.; Martinez, A.; Andraud, C.; Maury, O. Org. Biomol. Chem. 2009, 7, 3086-3090.

19 The alternating cyanine described in reference 16 presents a BLA of $10 \mathrm{pm}$ but posses a conjugated chain composed by only three carbon atoms.

20 Since $\mathbf{2}$ is not soluble in toluene, the comparison should not be made in the same solvent. 
${ }^{22}$ M. J. Frisch, G. W. Trucks, H. B. Schlegel, G. E. Scuseria, M. A. Robb, J. R. Cheeseman, J. A. Montgomery, Jr., T. Vreven, K. N. Kudin, J. C. Burant, J. M. Millam, S. S. Iyengar, J. Tomasi, V. Barone, B. Mennucci, M. Cossi, G. Scalmani, N. Rega, G. A. Petersson, H. Nakatsuji, M. Hada, M. Ehara, K. Toyota, R. Fukuda, J. Hasegawa, M. Ishida, T. Nakajima, Y. Honda, O. Kitao, H. Nakai, M. Klene, X. Li, J. E. Knox, H. P. Hratchian, J. B. Cross, V. Bakken, C. Adamo, J. Jaramillo, R. Gomperts, R. E. Stratmann, O. Yazyev, A. J. Austin, R. Cammi, C. Pomelli, J. W. Ochterski, P. Y. Ayala, K. Morokuma, G. A. Voth, P. Salvador, J. J. Dannenberg, V. G. Zakrzewski, S. Dapprich, A. D. Daniels, M. C. Strain, O. Farkas, D. K. Malick, A. D. Rabuck, K. Raghavachari, J. B. Foresman, J. V. Ortiz, Q. Cui, A. G. Baboul, S. Clifford, J. Cioslowski, B. B. Stefanov, G. Liu, A. Liashenko, P. Piskorz, I. Komaromi, R. L. Martin, D. J. Fox, T. Keith, M. A. Al-Laham, C. Y. Peng, A. Nanayakkara, M. Challacombe, P. M. W. Gill, B. Johnson, W. Chen, M. W. Wong, C. Gonzalez, and J. A. Pople, Gaussian, Inc., Wallingford CT, 2004.

${ }^{23}$ Lee, C. T.; Yang, W. T.; Parr, R. G. Phys. Rev. B 1988, 37, 785-789

${ }^{24}$ Becke, A. D. J. Chem. Phys. 1993, 98, 5648-5652.

25 Sheldrick, G.M. (1997).SHELX97. Program for the Refinement of Crystal Structures, Univ. of Göttingen, Germany. 